\title{
Ozone Gas Inhibits SARS-CoV-2 Transmission and Provides Possible Control Measures
}

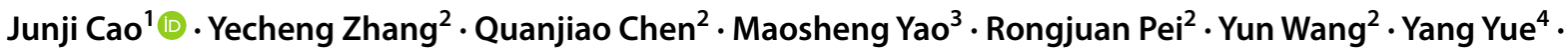 \\ Yu Huang ${ }^{1}$. Jing Wang ${ }^{4} \cdot$ Wuxiang Guan ${ }^{2}$
}

Received: 17 June 2021 / Revised: 7 August 2021 / Accepted: 10 August 2021 / Published online: 20 August 2021

(c) Institute of Earth Environment, Chinese Academy Sciences 2021

\begin{abstract}
The novel severe acute respiratory syndrome coronavirus 2 (SARS-CoV-2) has caused millions of deaths currently. Mounting effective responses to the pandemic have become top priorities for governments around the world. Laboratory experiments have confirmed for the first time that fumigation with ozone $\left(\mathrm{O}_{3}\right)$ at low $\mathrm{O}_{3}$ doses $\left(7500-15,000 \mu \mathrm{g} \mathrm{m}^{-3} \cdot \mathrm{min}\right)$ can inhibit the SARS-CoV-2 and inactivate the virus at high $\mathrm{O}_{3}$ doses $\left(129,000 \mu \mathrm{g} \mathrm{m}^{-3} \cdot \mathrm{min}\right)$. The RNA copy number of SARS-CoV-2 significantly decreased (95.9-97.7\% reduction) when exposed to $\mathrm{O}_{3}$ at a low concentration of $250 \mu \mathrm{g} \mathrm{m}^{-3}$ for 30 and 60 min. A significant negative relationship between the numbers of confirmed SARS-CoV-2 cases and ambient $\mathrm{O}_{3}$ in Chinese cities indicated that the spread of SARS-CoV-2 may have been inhibited by high $\mathrm{O}_{3}$. An analysis of data from Chongqing showed that the transmission of COVID-19 increased when the $\mathrm{O}_{3}$ mixing ratios in the air were relatively low, and transmission decreased when $\mathrm{O}_{3}$ increased. Based on these findings, we also propose a new Safety $\mathrm{O}_{3}$ Emission (SOE) method to increase indoor $\mathrm{O}_{3}$ to levels $\left(<160 \mathrm{\mu g} \mathrm{m}^{-3}\right)$ that inhibit the transmission of the SARS-CoV-2 but are not harmful for humans. This could serve as timely and low-cost solution for suppressing COVID-19 outbreaks throughout the world.
\end{abstract}

Keywords Inactivation of SARS-CoV-2 $\cdot$ Ambient $\mathrm{O}_{3} \cdot$ Active SOE control

\section{Introduction}

The outbreak of COVID-19 respiratory disease caused by the novel coronavirus SARS-CoV-2 (severe acute respiratory syndrome coronavirus 2) has aroused public health concerns around the world (Hu et al. 2020). The virus has been found in more than 200 countries and caused widespread disease and death. As of June 2021, more than 170 million confirmed cases have been reported globally and hundreds

Junji Cao

jjcao@ieecas.cn

$\bowtie$ Wuxiang Guan guanwx@wh.iov.cn

1 Key Lab of Aerosol Chemistry and Physics, SKLLQG, Institute of Earth Environment, Chinese Academy of Sciences, Xi' an, China

2 Wuhan Institute of Virology, Center for Biosafety Mega-Science, Chinese Academy of Sciences, Wuhan, China

3 Peking University, Beijing, China

4 Institute of Environmental Engineering, ETH Zürich, 8093 Zurich, Switzerland of thousands of deaths have occurred (https://news.ifeng. $\mathrm{com} / \mathrm{c} / \mathrm{special} / 7 \mathrm{uLj} 4 \mathrm{~F} 83 \mathrm{Cqm}$ ? needpage $=1 \&$ webkit $=1$ ). The latest outbreak of the new SARS-CoV-2 in July 2021 at Nanjing, China (https://mp.weixin.qq.com/s/Uj2ipOmo71 cr8ertLHXuGg) indicates that new viruses are more likely to spread rapidly through the air and bring new disasters to human society. Mobilizing the resources needed to combat the disease has led to a variety of challenges for governments around the world (Atkinson 2020).

The main transmission pathways for SARS-CoV-2 are direct physical contact and airborne transmission (Morawska and Cao 2020; Hu et al. 2020). The spread of virus through the air usually occurs through aerosolized droplets over short distances and aerosol particles at medium and longer distances (Tellier et al. 2019; Morawska and Cao 2020; Morawska et al. 2021). The development of methods for inactivating viruses and curbing the spread of disease has become a top priority for limiting the impact of COVID-19. Currently, ambient temperature (Bannister-Tyrrell 2020) and ultraviolet light are considered to be the main environmental factors that affect the spread of SARS-CoV-2. The focus of the 
study presented here is on ozone, a ubiquitous atmospheric trace gas that has both natural and anthropogenic sources.

Ozone molecules $\left(\mathrm{O}_{3}\right)$ directly react with biomolecules, and $\mathrm{O}_{3}$ also can decompose to form free radicals that react with biomolecules (Elvis and Ekta 2011). $\mathrm{O}_{3}$ also has been proven to have inactivating effects on the first SARS virus (Zhang et al. 2004), influenza virus (Tanaka et al. 2009), and other viruses (Hudson et al. 2009). These studies have shown that on a timescale of around a minute, $\mathrm{O}_{3}$ can affect the internal structure of the viruses and damage nucleic acids. $\mathrm{O}_{3}$ in the air also has been shown to have a negative association the influenza virus (Ali et al. 2018), and these authors proposed that there may be $\mathrm{O}_{3}$-primed immunity against a variety of influenza virus types and subtypes. Therefore, the possibility that fumigation with $\mathrm{O}_{3}$ could affect the survival of SARS-CoV-2 in the air and the transmission of the disease has attracted our attention. The main purposes of this paper are (1) to investigate inhibitory effects of $\mathrm{O}_{3}$ on SARS-CoV-2 through laboratory experiments and statistical analysis and (2) to propose active control methods.

\section{Materials and Methods}

\subsection{Virus Culture and $\mathrm{O}_{3}$ Treatment}

Vero-E6 cells (ATCC CRL-1586) were cultured in Dulbecco's minimal essential medium supplemented with
$10 \%$ fetal bovine serum (FBS, Thermo Fisher Scientific, Thornton, Australia) with 100 units $\mathrm{ml}^{-1}$ penicillin and $1 \mathrm{mg} \mathrm{ml}^{-1}$ streptomycin (Invitrogen, NY, USA) in a humidified $37{ }^{\circ} \mathrm{C}$ incubator with $5 \% \mathrm{CO}_{2}$. An ozone generator (MAXP-ARS50, Maxell, Japan) was used as the source of ozone gas to investigate the survival of viruses when exposed to different $\mathrm{O}_{3}$ concentrations in a $3.2 \mathrm{~L}$ chamber. $200 \mu \mathrm{l} \mathrm{SARS-CoV-2}\left(4 \times 10^{3}\right.$ plaque forming units, pfu) were transferred onto $2 \mathrm{~cm} \times 2 \mathrm{~cm}$ gauze cloths followed by $\mathrm{O}_{3}$ treatment at different concentrations for $30 \mathrm{~min}$ or $60 \mathrm{~min}$ as indicated in Fig. 1. The gauze cloths were soaked in $250 \mu \mathrm{l}$ phosphate buffer saline (PBS) for $5 \mathrm{~min}$, and the supernatants were collected for Vero-E6 inoculations. The inoculated cells were cultured for $24 \mathrm{~h}$ prior to RNA extraction.

\subsection{RNA Extraction}

The culture supernatants were harvested $24 \mathrm{~h}$ post inoculation for RNA extraction. For this, $0.5 \mathrm{ml}$ of TRIzol ${ }^{\mathrm{TM}}$ Reagent (Invitrogen, NY, USA) was added to $0.5 \mathrm{ml}$ of each supernatant. The viral RNA was isolated following a standard protocol according to the manufacturer's instructions and dissolved in $20 \mu \mathrm{l}$ of diethyl pyrocarbonate (DEPC)-treated water.

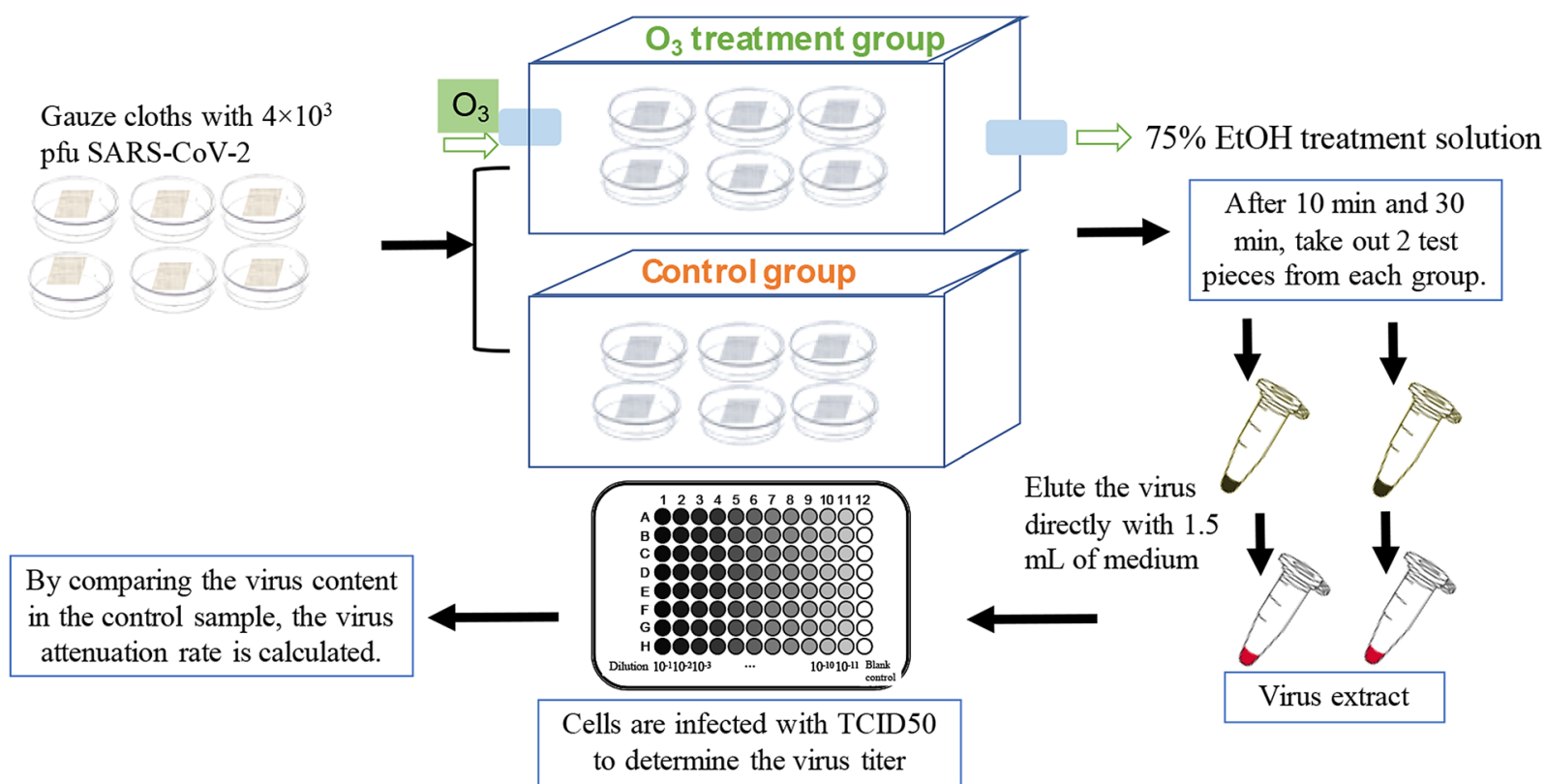

- The reaction environment of the $\mathrm{O}_{3}$ treatment group use a sealed small box to facilitate the calculation of the ozone concentrations.

- The control group is the indoor temperature and humidity environment.

Fig. 1 Flowchart of $\mathrm{O}_{3}$ treatment experiment in this study 


\subsection{Quantitative Reverse Transcription Polymerase Chain Reaction Methods}

A quantitative reverse transcription polymerase chain reaction (qRT-PCR) technique was performed using One Step PrimeScript $^{\mathrm{TM}}$ RT-PCR kits (Perfect Real Time, Takara, RR064A), following the standard protocol provided by the manufacture. The Orflab primers (Orflab-F: 5'-CCC TGT GGG TTT TAC ACT TAA-3', Orflab-R: 5'-ACG ATT GTG CAT CAG CTG A-3') and probe (Orflab-P 5'-FAM-CCG TCT GCG GTA TGT GGA AAG GTT ATG G-BHQ1-3') were used. The $N$ gene primers ( $N$-F: 5'-GGG GAA CTTC TCC TGC TAG AAT- $3^{\prime}, N$-R: $5^{\prime}$ - CAG ACA TTT TGC TCT CAA GCT G-3') and probe ( $N$-P 5'-FAM-TTG CTG CTG CTT GAC AGA TT-TAMRA-3') were used to confirm the RNA samples. Viral genome copy numbers were calculated based on a standard curve generated from the in vitro transcribed RNAs that contained the PCR amplicon. All the primers were designed referring to the SARS-CoV-2 genome (GISAID, https://www.gisaid.org/, accession number: EPIISL-402124) (1).

\subsection{Data Collection and Statistic Analysis}

For the statistical analyses, confirmed cases of SARS-CoV-2 were obtained from the IFENG News website (https://news. ifeng.com/c/special/7tPIDSzDgVk? from=singlemessage \& isappinstalled $=0$ ). The ambient average ground level $\mathrm{O}_{3}$ concentrations at 30 provincial capital cities in mainland China (except Wuhan) were calculated for one month from 22 January to 21 February 2020 based on real-time observations in the Chinese Environmental Monitoring Network (https://beijingair.sinaapp.com). Software of Igor Pro 8 (WaveMetrics, Inc., USA) was utilized for statistic analyses and plotting.

\section{Results and Discussion}

\subsection{Inactivation of SARS-CoV-2 with Ambient $\mathrm{O}_{3}$ in Laboratory Studies}

To investigate possible effects of $\mathrm{O}_{3}$ on SARS-CoV-2, we studied the survival of the virus under different concentrations of $\mathrm{O}_{3}$ in combination for various exposure times in the Biosafety Level III laboratory (Fig. 2). For this, diluted virus was spotted on the gauze cloth and treated with $\mathrm{O}_{3}$ for the test conditions as indicated (Fig. 2) followed by washing with the medium used for virus culture. The qRT-PCR targeting SARS-CoV-2 Orflab gene was performed to check the viral genomic copy number $24 \mathrm{~h}$ after inoculation. We found that the RNA copy number of SARS-CoV-2 significantly decreased to $95.9 \%$ for $30 \mathrm{~min}$ and $97.7 \%$ for $60 \mathrm{~min}$

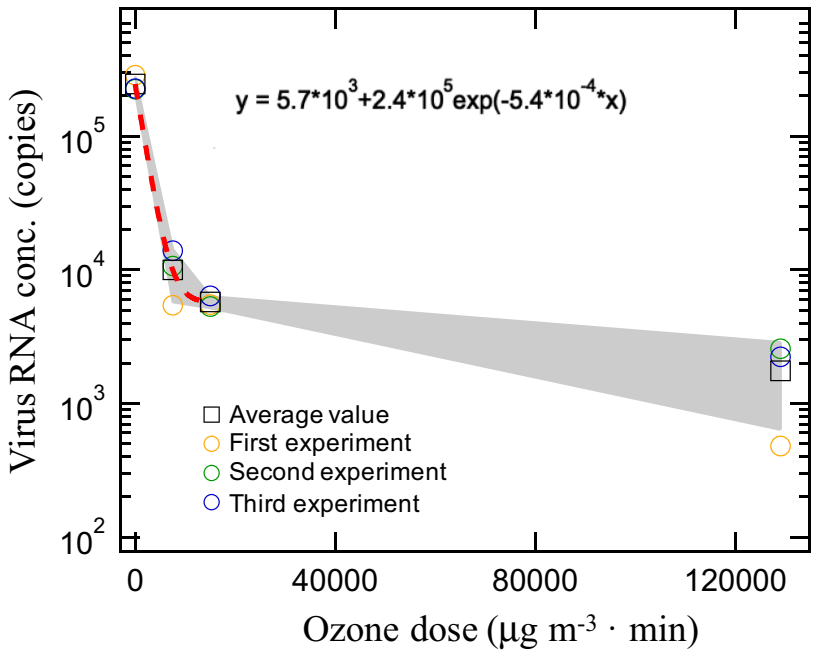

Fig. 2 Inactivation SARS-CoV-2 effect of $\mathrm{O}_{3}$ under different doses. $4 \times 10^{3}$ pfu SARS-CoV-2 were transferred onto gauze cloths followed by $\mathrm{O}_{3}$ treatment at low concentrations $\left(250 \mu \mathrm{g} \mathrm{m}^{-3}\right)$ for $30 \mathrm{~min}$ and $60 \mathrm{~min}$, or at high concentration $\left(4700 \mu \mathrm{g} \mathrm{m}^{-3}\right)$ for $30 \mathrm{~min}$ in a simulation chamber $(3.2 \mathrm{~L})$. The viral genomic RNA copy number was quantified by qRT-PCR. The red dotted line is the exponential fit line under low ozone dose (under ambient $\mathrm{O}_{3}$ concentration of $250 \mu \mathrm{g} \mathrm{m}^{-3}$ ). The shaded area shows one standard deviation of the experimental data. All the experiments were repeated at least three times (different color in the figure)

on average when the test cloths were fumigated with $\mathrm{O}_{3}$ at a low concentration of $250 \mu \mathrm{g} \mathrm{m}^{-3}$ (high hourly ambient $\mathrm{O}_{3}$ concentration). The RNA concentrations of SARS-CoV-2 showed exponential decreases with $\mathrm{O}_{3}$ dose (exposure time [min] multiplied by ozone concentration $\left[\mu \mathrm{g} \mathrm{m}^{-3}\right]$ ) (the red line in Fig. 2 is the fitted line for RNA variations at the low ozone dose), which indicates that some of the SARS-CoV-2 was inactivated by $\mathrm{O}_{3}$.

To further investigate possible effects of $\mathrm{O}_{3}$ on virus, we fumigated SARS-CoV-2 inoculated cloths to a higher concentration of $\mathrm{O}_{3}\left(4700 \mu \mathrm{g} \mathrm{m}^{-3}\right)$ for $30 \mathrm{~min}$. Results of these studies showed that the RNA concentrations of SARS-CoV-2 at the higher $\mathrm{O}_{3}$ dose decreased to close detection limits compared with that of control group (Fig. 2). Indeed, almost all the SARS-CoV-2 was inactivated at the high ozone dose $\left(129,000 \mu \mathrm{g} \mathrm{m}^{-3} \cdot \mathrm{min}\right)$. Therefore, our results showed for the first time that a low $\mathrm{O}_{3}$ dose (ambient concentration level) in the environment can inhibit SARS-CoV-2 and a high $\mathrm{O}_{3}$ dose can nearly completely inactivate the virus.

\subsection{Relationship Between SARS-CoV-2 and Ambient $\mathrm{O}_{3}$ in China}

Understanding the environmental factors that affect SARS-CoV-2 will be helpful for predicting how coronaviruses spread. Temperature, humidity, $\mathrm{O}_{3}$, UV light, etc. are all thought to possibly affect the transmission of the 
SARS-CoV-2 (Yao et al. 2020; Bannister-Tyrrell 2020), but there is little direct evidence for any such effects. To investigate this, we conducted a statistical analysis of the relationship between selected environmental factors and COVID-19 cases when SARS-CoV-2 began to spread in major cities in China; that is, from 22 January to 21 February 2020.

We found that several environmental factors such as temperature, humidity, solar radiation, and UV were not correlated with the numbers of COVID-19 cases (all $R^{2}<0.1$ ); however, $\mathrm{O}_{3}$ concentrations were significantly correlated with COVID-19 cases. This finding was consistent with the finding of Yao et al. (2020). Figure 3 shows the geographical distribution of the confirmed COVID-19 cases and the relationship between the numbers of COVID cases and $\mathrm{O}_{3}$ for a group of large Chinese cities during February 2020. A linear regression of the number of COVID-19 cases in each city versus $\mathrm{O}_{3}$ mixing ratios showed a significant negative correlation, with $R^{2}=0.23(p \leq 0.05)$.

The dataset and analyses have limitations because information on how the disease was transmitted was not available, that is, whether it was by direct contact or through the air. If the numbers of airborne transmission cases could be separated from those caused by direct contact, the relationship to $\mathrm{O}_{3}$ might become clearer. This highlights the point that whenever possible, it would be highly desirable for epidemiological data records to have an indication of how the disease was acquired.

Our analyses also showed that Chinese cities with relatively high $\mathrm{O}_{3}$, such as Lhasa, Xining, and Yinchuan (shown in Fig. 3a), had lower incidences of infection while those with lower $\mathrm{O}_{3}$, such as Beijing and Chongqing, tended to have more cases. The $\mathrm{O}_{3}$ concentrations in Lhasa, Hai Kou, and Xining were $72 \mu \mathrm{g} \mathrm{m}^{-3}, 71 \mu \mathrm{g} \mathrm{m}^{-3}$, and $69 \mu \mathrm{g} \mathrm{m}^{-3}$, respectively, and the corresponding cases were 1 (no secondary infection cases), 12, and 16 (Fig. 3a). The $\mathrm{O}_{3}$ concentrations in Beijing and Chongqing were $50 \mu \mathrm{g} \mathrm{m}^{-3}$ and $36 \mathrm{~g} \mathrm{~m} \mathrm{~m}^{-3}$, respectively, and the corresponding numbers of cases were 393 and 561 (Fig. 3a).

Taking Chongqing as an example of a typical city with a large number of SARS-CoV-2 infections, we plotted a time-series of the number of daily COVID-19 cases versus the $\mathrm{O}_{3}$ concentrations from 23 January to 21 February 2020 (Fig. 4). The $\mathrm{O}_{3}$ data plotted are the averages for 5 days before the case reports because COVID-19 typically has an incubation period of $\sim 3-5$ days (Guan et al. 2020; Zhu et al. 2020). In other words, we assumed that the $\mathrm{O}_{3}$ average accumulated concentrations in 5 days before the incidence of disease reports would be a better indicator of the relationship than the concurrent data because of the time lag between exposure and the onset of the disease. Large numbers of COVID-19 cases in Chongqing corresponded with low $\mathrm{O}_{3}$ (Fig. 4a), and a strong negative relationship was found between the number of cases and $\mathrm{O}_{3}$ concentrations $\left(R^{2}=0.42, p<0.01\right)$ (Fig. $\left.4 \mathrm{~b}\right)$. This finding implies a possible role of ambient $\mathrm{O}_{3}$ in the control of transmission of COVID-19.

\subsection{Comparison of Methods for Disinfecting Air}

The airborne route of the SARS-CoV-2 is believed to be important means for transmission because viral particles can be expelled into the air with an infected person's exhalations. Furthermore, the virus can be suspended in the air for a considerable amount of time because the particles are small, $100 \mathrm{~nm}$ in size (Morawska and Cao 2020; Liu et al. 2020). In fact, SARS-CoV-2 has been detected in various
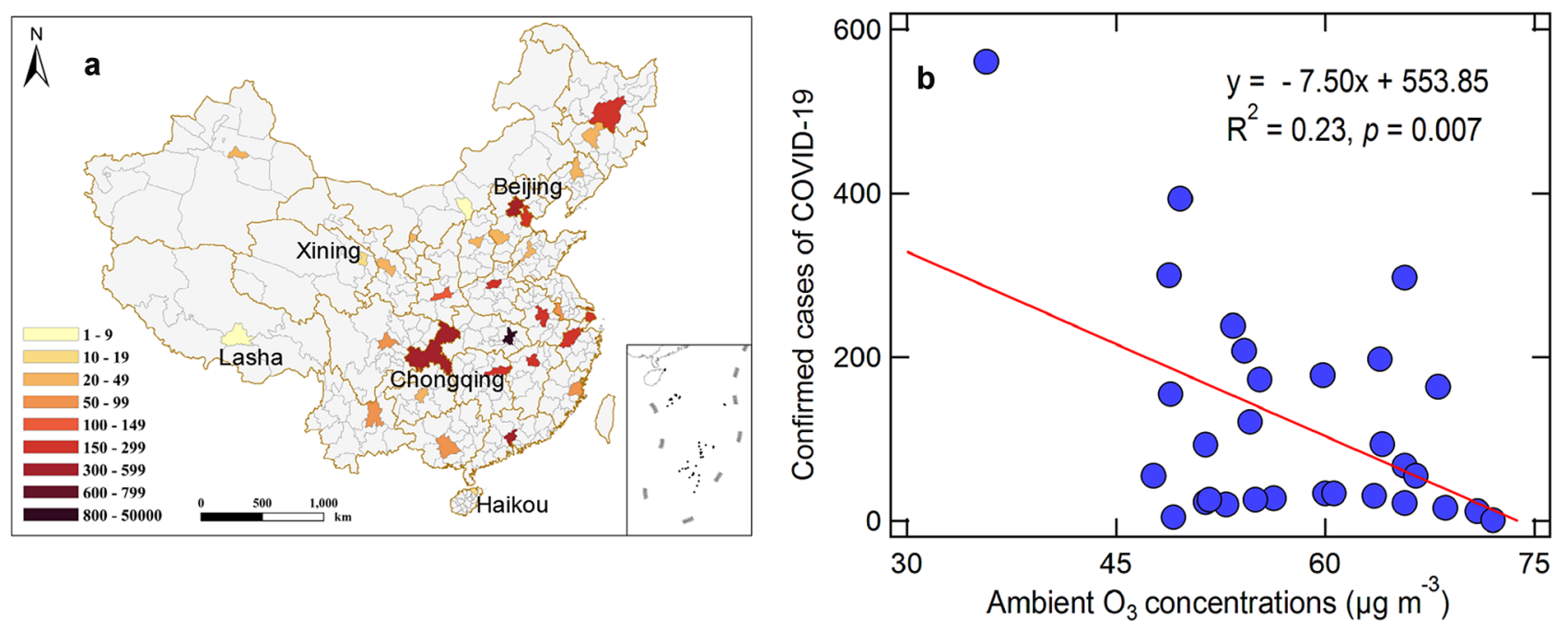

Fig. 3 Confirmed cases of COVID-19 (a) and its relationship (b) with ambient $\mathrm{O}_{3}$ concentrations in major Chinese cities. Software of Igor Pro 8 (WaveMetrics, Inc., USA) was utilized for statistic analyses and plotting 

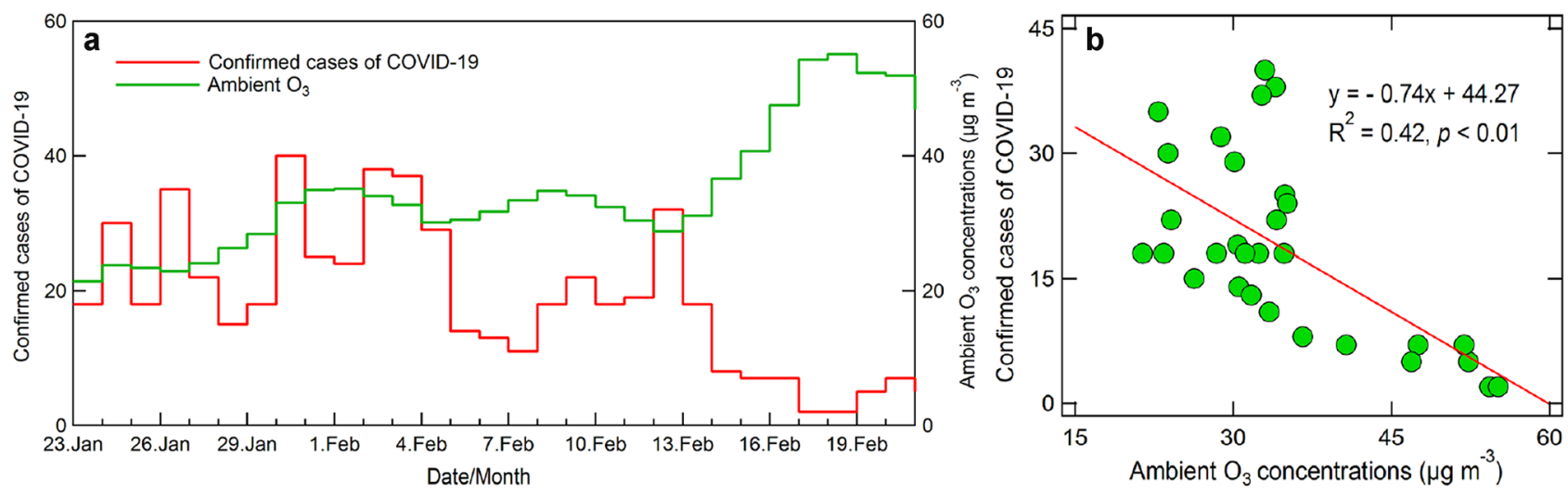

Fig. 4 Time-series plot of a confirmed cases of COVID-19 and $\mathbf{b}$ relationship between COVID-19 and ambient $\mathrm{O}_{3}$ concentrations in Chongqing, China. Software of Igor Pro 8 (WaveMetrics, Inc., USA) was utilized for statistic analyses and plotting

microenvironments near infected patients, implying that the virus is spread through the air and infectious particles are deposited onto surfaces (To et al. 2020). Until a vaccine becomes available, public health measures will be the most important means to prevent the spread of SARS-CoV-2.

Air disinfection methods, such as exposure to UV radiation, have been proposed as a way to prevent the spread of SARS-CoV-2 (https://www.cnbc.com/2020/05/10/howultraviolet-light-could-help-stop-the-spread-of-covid-19. html?__source=iosappshare\%7Ccom.tencent.xin.sharetimel ine). Improving ventilation is another low-cost approach for reducing the concentrations of respiratory viruses in the air (WHO 2009), and some studies have shown that improvements in ventilation could effectively mitigate the spread of some viruses. For example, Smieszek et al. (2019) concluded that upgrading ventilation could have the same mitigating effect as vaccinating $50-60 \%$ of the population for the control of influenza.

Taking these results into account, we propose an $\mathrm{O}_{3}$ disinfection method to help control the transmission of SARS-CoV-2 and other airborne viruses. Disinfection with $\mathrm{O}_{3}$ is a widely accepted and mature method for preventing the spread of airborne pathogens, and it is commonly used in China and other countries (Tanaka et al. 2009; Hudson et al. 2009; Elvis and Ekta 2011). Ozone rapidly inactivates suspended viruses, and it disinfects by permeation, leaving few areas untreated. Moreover, at low concentrations, ozone is not harmful to humans and there are no toxic by-products (Guzel-Seydim et al. 2004); in fact, $\mathrm{O}_{3}$ decomposes into $\mathrm{O}_{2}$ at room temperature and pressure in $\sim 30 \mathrm{~min}$.

Air purifiers are another option for the control of airborne virus. We tested a new type of air purifier with plasma and high filtration technology that was deployed in tests to see if the device could reduce the concentrations of SARS-CoV-2 in the air of a CT (Computed Tomography) room at a Hospital. The results show that the concentration of viral RNA copies decreased from $8.95 \times 10^{3}$ to undetectable levels after the air purifier operated for one hour in the indoor environment with viral aerosols at the Hospital's CT room.

Table 1 summarizes and compares four methods commonly used for air disinfection. Due to its practical advantages and low cost, fumigation with $\mathrm{O}_{3}$ should be considered as means for suppressing the airborne transmission of viruses. As noted above, high concentrations of $\mathrm{O}_{3}$ can inactivate viruses in the air and decontaminate environmental surfaces. Furthermore, we note that ozone already is being widely used for disinfecting medical equipment, medicines, food, water, etc. (Viebahn-Hänsler et al. 2012; Guzel-Seydim et al. 2004; Von Sonntag 2012). Therefore, ozone has potential applications for inactivating SARS$\mathrm{CoV}-2$ in enclosed areas, especially in hospitals and public buildings.
Table 1 Comparison of four methods for air disinfection

\begin{tabular}{lllll}
\hline Method & Approach & Advantages & Disadvantages & Cost \\
\hline Ventilation & Passive & Easy operation & Dilutes the virus but does not inactivate it & Low \\
UV light & Active & High efficacy & Limited by where light can reach & Middle \\
$\mathrm{O}_{3}$ fumigation & Active & High efficacy & Negative impact under high concentration & Low \\
Air purifier & Active & High efficacy & Low flow rates & High \\
\hline
\end{tabular}




\subsection{Active Safety $\mathrm{O}_{3}$ Emission (SOE) Method for Inactivating SARS-CoV-2}

While much of the focus of controlling the virus has been on finding infected persons, isolation and quarantine, social distancing, and hand hygiene, Morawska et al (2020) proposed that a parallel reduction in airborne transmission would help combat the virus. This basis of that proposal was that engineering controls in hospitals and other public buildings could protect healthcare workers, patients, and the general public alike. Here, we propose a Safety $\mathrm{O}_{3}$ Emission (SOE) method for inactivating SARS-CoV-2 for indoor microenvironments.

The concentration of ozone in the Chinese environmental (outdoor) atmospheric standard is $160 \mu \mathrm{g} \mathrm{m}^{-3}$ according to GB3095 2012. This concentration is the maximum daily average $8 \mathrm{~h}$ value for second-class areas, which include residential areas, mixed commercial and residential areas, cultural areas, industrial areas, and rural areas. The Chinese indoor air standard is also $160 \mu \mathrm{g} \mathrm{m}^{-3}$ (hourly average, GB/T 18883-2002). Taking these air quality standards and the $\mathrm{O}_{3}$ concentration required to inactivate viruses into consideration, we propose that $\mathrm{O}_{3}$ in indoor air could be increased to a level that would inactivate the SARS-CoV-2 without unwanted effects on human health. As exposure to elevated $\mathrm{O}_{3}$ can be harmful for sensitive persons, we recognize that the use of $\mathrm{O}_{3}$ for virus control would not be advisable for all situations.

The Safety $\mathrm{O}_{3}$ Emission (SOE) method we propose would raise the $\mathrm{O}_{3}$ concentration to $160 \mu \mathrm{g} \mathrm{m}^{-3}$ to inactivate the SARS-CoV-2 suspended in indoor air and on contaminated surfaces. To estimate the costs associated with the SOE method, we conducted a study in a $420 \mathrm{~m}^{3}$ conference room. The installation cost of the purification equipment was 900 RMB or $\sim \$ 125$ USD (Fig. 5). After $30 \mathrm{~min}$, the indoor $\mathrm{O}_{3}$ concentration in the room reached $160 \mu \mathrm{g} \mathrm{m}^{-3}$. If the room air were fully exchanged once each hour in an $8 \mathrm{~h}$ work day, the cost of electricity to power the instrument would be inconsequential, only 0.8 RMB. Thus, the installation cost of ozone equipment would be $\sim 2 \mathrm{RMB} \mathrm{m}^{-3}$ for indoor spaces, and the operating electricity cost $\sim 0.1 \mathrm{RMB} \mathrm{h}^{-1}$. These results show that the implementation of the SOE could be an extremely cost-effective way to combat the spread of viral pathogens.

The cost of producing $1 \mathrm{~g}$ of pure $\mathrm{O}_{3}$ gas per hour is 50-100 RMB, using air or pure oxygen as the starting materials, and its production requires only an $\mathrm{O}_{3}$ generator and electrical power. To ensure that the $\mathrm{O}_{3}$ concentrations in the indoor spaces were at safe levels, $\mathrm{O}_{3}$ microsensors could be installed at the same time as the $\mathrm{O}_{3}$ generators for real-time monitoring and management from a cloud-based data platform - this is a mature technology in China. Indeed, the SOE method could be applied to various enclosed/semi-enclosed

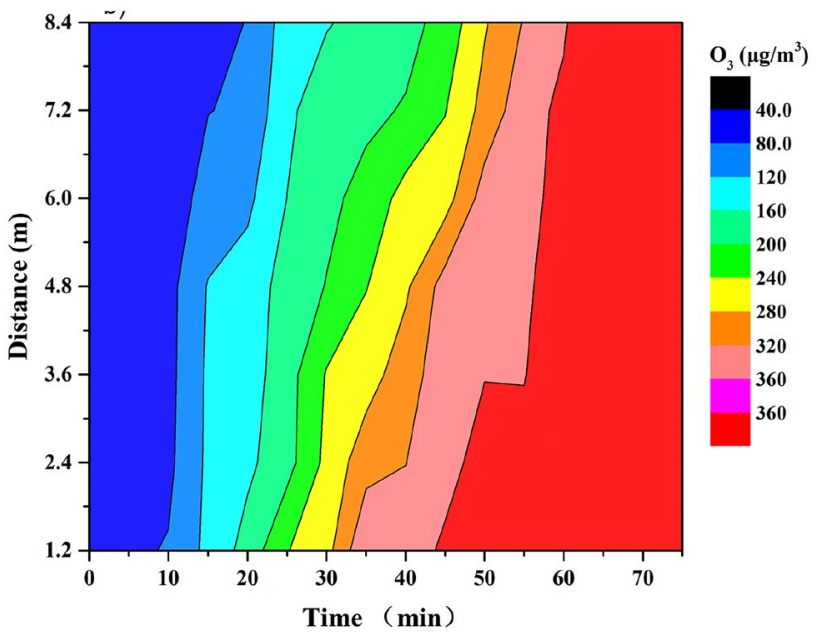

Fig. 5 Distribution of $\mathrm{O}_{3}$ with time in an experimental room. The concentration of $\mathrm{O}_{3}$ was monitored (Model 205, 2B-tech, USA) and plotted with time variation after the startup of an $\mathrm{O}_{3}$ generator

spaces such as school, offices, conference rooms, office buildings, shopping malls, restaurants, elevators, railway stations, and subway stations nationwide to provide extremely low-cost air purification technology for the control of SARS$\mathrm{CoV}-2$ and other viruses and prevention of the diseases they cause.

Another potentially important and useful application of the SOE technology would be for transportation, including airplanes, ships, and trains. These can be considered indoor environments where people are often confined in close quarters for extended periods. Various diseases are commonly spread through transportation, and in this way, viruses and other pathogens can become rapidly dispersed over long distances. The final advantage of the $\mathrm{SOE}$ is that the $\mathrm{O}_{3}$ generation for both indoor environments and transportation can be quickly and easily turned on or off as the situation warrants. After the SARS-CoV-2 epidemic ends, the SOE methods could be used as preventive measures to protect against pathogens in the air and possibly adapted for the control of diseases that affect confined animal operations, such as the influenza and swine flu.

\section{Conclusions}

From a public health perspective, it is not known in detail how environmental factors affect the airborne transmission of SARS-CoV-2. Understanding the environmental drivers of the COVID-19 disease could contribute to the timely intervention and development of scientific control strategies for the SARS-CoV-2 virus. Our experimental results demonstrated for the first time that fumigation with $\mathrm{O}_{3}$ can (1) inhibit the SARS-CoV-2 at a low ambient $\mathrm{O}_{3}$ dose that 
should be safe for most persons and (2) inactive the virus at a higher dose. Through statistical analyses of the relationships between the numbers of SARS-CoV-2 cases and ambient $\mathrm{O}_{3}$ concentration, we found evidence that high concentrations of ambient $\mathrm{O}_{3}$ inhibit SARS-CoV-2 transmissibility. From our analyses, we suggest that increases in ambient $\mathrm{O}_{3}$ concentrations combined with other environmental factors, especially temperature and UV radiative fluxes, could slow the spread of SARS-CoV-2 in the environment. We proposed a new SOE method designed to mitigate the transmission of coronavirus as well as limit the occurrence of superspreader events in indoor air by increasing $\mathrm{O}_{3}$ concentrations. The method could be considered as a low-cost air purification solution to rapidly combat the SARS-CoV-2 epidemic.

Acknowledgements The authors thank Dr. Richard Arimoto and Prof. Phil Landrigan for participating in insightful discussions and valuable suggestions. We also thank Cui Long for his assistance with the indoor experiments. This research is supported by the Chinese Academy of Science.

\section{Declarartions}

Conflict of Interest Dr. Junji Cao and Dr. Yu Huang are Editorial Board members for Aerosol Science and Engineering.

\section{References}

Ali ST et al (2018) Ambient ozone and influenza transmissibility in Hong Kong. Eur Respir J 51:1800369

Atkinson C (2020) G20 leaders must answer to COVID-19. Science 368(6487): 111

Bannister-Tyrrell M et al (2020) Preliminary evidence that higher temperatures are associated with lower incidence of COVID-19, for cases reported globally up to 29th February 2020. medRxiv Preprint. https://doi.org/10.1101/2020.03.18.20036731

David LM, Ravishankara AR, Brewer JF et al (2019) Tropospheric ozone over the Indian subcontinent from 2000 to 2015: data set and simulation using GEOS-Chem chemical transport model. Atmos Environ 219:117039

Elvis AM, Ekta JS (2011) Ozone therapy: a clinical review. J Natl Sci Biol Med 2(1):66

European Centre for Disease Prevention and Control website (2021) https://www.ecdc.europa.eu/en

Guan WJ, Ni ZY, Hu Y et al (2020) Clinical characteristics of 2019 novel coronavirus infection in China. N Engl J Med. https://doi. org/10.1056/NEJMoa2002032

Guzel-Seydim ZB, Greene AK, Seydim AC (2004) Use of ozone in the food industry. LWT-Food Sci Technol 37(4):453-460

$\mathrm{Hu}$ J, Lei CF, Chen $\mathrm{Z}$ et al (2020) Distribution of airborne SARSCoV-2 and possible aerosol transmission in Wuhan hospitals, China. Natl Sci Rev 7:1865-1867. https://doi.org/10.1093/nsr/ nwaa250

Hudson JB, Sharma M, Vimalanathan S (2009) Development of a practical method for using ozone gas as a virus decontaminating agent. Ozone Sci Eng 31(3):216-223. https://doi.org/10.1080/ 01919510902747969

Hui DS, Azhar E, Madani TA et al (2020) The continuing SARSCOV-2-19 epidemic threat of novel coronaviruses to global
health-The latest 2019 novel coronavirus outbreak in Wuhan China. Int J Infect Dis 91:264-266

Lai D, Karava P, Chen QY (2015) Study of outdoor ozone penetration into buildings through ventilation and infiltration. Build Environ 93:112-118

Lee SH (2003) The SARS epidemic in Hong Kong. J Epidemiol Community Health 57:652-652

Liu YL, Ning Z, Chen Y, Guo M, Liu Y, Gali NK, Sun L, Duan Y, Cai J, Westerdahl D, Env D, Liu X, Ho K, Kan H, Fu Q, Lan K (2020) Aerodynamic analysis of SARS-CoV-2 in two Wuhan hospitals. Nature 582:557-560

Morawska L, Cao JJ (2020) Airborne transmission of SARS-CoV-2: the world should face the reality. Environ Int 139:105730

Morawska L, Tang JW, Bahnfleth W et al (2020) How can airborne transmission of COVID-19 indoors be minimised? Environ Int 142(2020): 105832

Morawska L, Allen J, Bahnfleth W et al (2021) A paradigm shift to combat indoor respiratory infection. Science 372(6543):689-691

Munir S, Habeebullah TM, Mohammed AMF, et al. (2015) An analysis into the temporal variations of ground level ozone in the arid climate of Makkah applying k-means algorithms. Environ Asia, 8(1)

Park SW, Bolker BM, Champredon D et al (2020) Reconciling earlyoutbreak estimates of the basic reproductive number and its uncertainty: framework and applications to the novel coronavirus (2019-nCoV) outbreak. medRxiv Preprint. https://doi.org/10. 1101/2020.01.30.20019877

Peeri NC, Shrestha N, Rahman M et al (2020) The SARS, MERS and novel coronavirus (COVID-19) epidemics, the newest and biggest global health threats: what lessons have we learned? Int J Epidemiol. https://doi.org/10.1093/ije/dyaa033

Porter WC, Khalil MAK, Butenhoff CL et al (2014) Annual and weekly patterns of ozone and particulate matter in Jeddah, Saudi Arabia. J Air Waste Manag Assoc 64(7):817-826

Quarcoo MA, Strickland PO, Shendell DG (2019) Indoor ozone estimation from outdoor ozone and LBNL relocatable classroom study data. Atmos Environ 213:491-498

Salonen H, Salthammer T, Morawska L (2018) Human exposure to ozone in school and office indoor environments. Environ Int 119:503-514

Shao M, Tang XY, Zhang YH et al (2006) City clusters in China: air and surface water pollution. Front Ecol Environ 4(7):353-361

Smieszek T, Lazzari G, Salathe M (2019) Assessing the dynamics and control of droplet- and aerosol- transmitted influenza using an indoor positioning system. Sci Rep 9:2185. https://doi.org/10. 1038/s41598-019-38825-y

Sweet F, Kao MS, Lee SCD et al (1980) Ozone selectively inhibits growth of human cancer cells. Science 209:931-932

Tanaka H, Sakurai M, Ishii K et al (2009) Inactivation of influenza virus by ozone gas. IHI Eng Rev 42(2):108-111

Tellier R, Li YG, Cowling BJ et al (2019) Recognition of aerosol transmission of infectious agents: a commentary. BMC Infect Dis 19(101):1-9

To KKW, Tsang OTY, Leung WS et al (2020) Temporal profiles of viral load in posterior oropharyngeal saliva samples and serum antibody responses during infection by SARS-CoV-2: an observational cohort study. Lancet Infect Dis. https://doi.org/10.1016/ S1473-3099(20)30196-1

Tseng CC, Li CS (2006) Ozone for inactivation of aerosolized bacteriophages. Aerosol Sci Technol 40(9):683-689

Viebahn-Hänsler R, León Fernández OS, Fahmy Z (2012) Ozone in medicine: the low-dose ozone concept—guidelines and treatment strategies. Ozone Sci Eng 34(6):408-424

Von Sonntag C, Von Gunten U (2012) Chemistry of ozone in water and wastewater treatment. IWA publishing

WHO (2009) Natural ventilation for infection control in health-care settings. 1-106 
Yao MS, Zhang L, Ma JX, Zhou L (2020) On airborne transmission and control of SARS-Cov-2. Sci Total Environ 731:139178

Zhang JM, Zheng CY, Xiao GF et al (2004) Examination of the efficacy of ozone solution disinfectant in inactivation SARS virus. Chin J Disinfect 21(1):27-28
Zhu N, Zhang D, Wang W et al (2020) A novel coronavirus from patients with pneumonia in China, 2019. N Engl J Med 382(8):727-733 